\title{
Florestan Fernandes e a educação
}

\author{
DERMEVAL SAVIANI
}

ODE-SE DIZER QUE AS preocupações educacionais acompanham toda a tra-
jetória de Florestan Fernandes manifestando-se em todas as facetas de sua
rica existência.

Para efeitos desse artigo destacarei quatro aspectos, a saber, a docência, a pesquisa, a militância e a publicística advertindo, preliminarmente, sobre a indissociabilidade desses aspectos, integrados que estão numa vida toda ela marcada pela coerência de propósitos reconhecida, aliás, como a principal característica de Marx (Fromm, 1967:220), com certeza o pensador com quem Florestan mais se identificava.

O primeiro aspecto enfoca a figura do professor Florestan, evidenciando o profundo significado educativo que marcou o seu magistério. O segundo aspecto destaca o lugar ocupado pela educação nas investigações científicas por ele realizadas. $\mathrm{O}$ terceiro refere-se ao seu engajamento na luta em defesa da educação pública, desde a campanha em defesa da escola pública até a sua atuação como deputado federal. Finalmente, o quarto aspecto coloca em evidência o publicista incansável, empenhado em divulgar sob todas as formas a seu alcance, a causa da defesa de uma escola pública de qualidade acessível a todos os brasileiros.

\section{O professor-educador}

O professor é, antes de tudo, um educador, isto é, formador de homens. Esta verdade simples que está na raiz da atividade docente tendeu, porém, a cair no esquecimento em benefício do aspecto mais visível da função docente que passou a ser entendido como a forma mesma do próprio ser do professor. Assim, à medida em que o magistério se institucionalizava através da constituição e expansão dos sistemas escolares, cristalizava-se essa compreensão restritiva do papel do professor. Daí, a separação entre instrução e educação e o conseqüente entendimento de que a tarefa da escola se limitava à instrução (Condorcet, 1989:56-72), definindo-se o professor como instrutor (instituteur, em francês). Estamos aí diante de uma ilustração da fundamental questão epistemológica segundo a qual a aparência não apenas esconde a essência mas pode tomar o lugar da própria essência. 
A radicalidade com que Florestan Fernandes assumiu a condição humana o levou a assumir também radicalmente as atividades em que se empenhou, aí incluída a ação docente. Nesse contexto, em lugar de se constituir simplesmente como um professor - sem dúvida sério, consistente e responsável, ministrando um ensino de qualidade a sucessivas turmas de alunos conforme a expectativa social e institucional estabelecida - foi levado a converter a cadeira de Sociologia I da Faculdade de Filosofia, Ciências e Letras da USP, que ficou sob sua responsabilidade a partir de 1952-53, num verdadeiro espaço educativo destinado a formar quadros de alto nível no campo das ciências sociais. Como ele próprio relata (Fernandes, 1972:82-83), já que não podia contar com um laboratório, como era o caso das ciências exatas, o que "impunha o trabalho em equipe" e "exigia modernização operacional de superficie e de fundo", a solução encontrada foi utilizar a cadeira de sociologia I como base de apoio para a constituição de uma equipe visando à "formação de um verdadeiro grupo de sociólogos pesquisadores", criando, ao mesmo tempo, "o espaço necessário à sua própria consolidação e crescimento gradual". Essa cadeira se transformou, pois, "em um pião para atingir fins que são inacessíveis ao professor e ao investigador isolados" (Ibid.:178).

O espaço pedagógico assim definido resultou $\mathrm{em}$ ambiente estimulante de um trabalho intelectual rico, intenso e exigente.

Por certo, como ele próprio frisou em diferentes oportunidades, Florestan não era um pedagogo e nem mesmo um cientista da cducação no sentido especializado que essas expressões adquiriram no século atual. Contudo, o senso de radicalidade já referido levou-o, a partir da experiência de sua própria formação e do processo formativo que passou a liderar como professor, a atuar como um verdadeiro educador, isto é, aquele que pratica a cducaçào com a consciência clara de que a está praticando, o que o leva a formular conceitos de máxima significação para o conhecimento da essência própria dos fenômenos educativos. Tomando em conta a sua trajetória nào será dificil cncontrar elementos que ilustram o que foi dito.

Assim, quando formula uma avaliação comparativa da sua formaçào no curso de graduação da Faculdade de Filosofia, Ciências e Letras da usp c no curso de mestrado na Escola Livre de Sociologia c Política, conclui: "em ambas as escolas os cursos monográficos eram de escollha arbitrária dos professores. $O$ que era ótimo para simplificar as tarefas docentes, mas péssimo em termos $d a$ quilo que deve aprender um estudante de ciências sociais" (Ibid.:170). Essa constatação revela a percepção clara da diferença de objetivos entre pesquisa (fazer crescer o saber), e ensino (fazer crescer o aluno) assim como da natureza propriamente pedagógica dos processos de ensino-aprendizagem, o que impõe a organização dos conteúdos segundo um plano cujo critério de referência deve ser dado pelos fins a atingir e não pela escolha arbitrária dos professores. 
Em outro momento, ao se referir ao que considera o "período mais fermentativo" de sua formação destaca duas atividades ligadas diretamente ao que fazia como professor e pesquisador na USP: "o ensino de sociologia e a pesquisa sociológica dobraram o meu rude individualismo, forçando-me a travar as últimas batalhas que assinalam o aparecimento de uma segunda natureza humana dentro de mim, a qual se confunde com o 'professor' e o 'sociólogo' em que me converti, inteiramente voltado para fora, para os 'problemas dos outros', os 'dilemas de nossa época' e o 'controle racional da mudança social"' (Ibid::171). Nesse ponto atinge-se o núcleo constitutivo da natureza da educação. E a própria expressão "segunda natureza", também já referida por Gramsci, assim como o conceito de babitus (Bourdieu-Passeron, 1970:46-70), remetem exatamente para a compreensão da essência da educação. Esses conceitos foram por mim (Saviani, 1995a:81-82) assumidos e sintetizados no conceito gramsciano de "catarse" entendido como a "assimilação superior da estrutura em superestrutura na consciência dos homens" (Gramsci, 1977:48) buscando identificar o ponto culminante do processo educativo que se define pelo "ato de produzir, direta e intencionalmente, em cada indivíduo singular, a humanidade que é produzida histórica e coletivamente pelo conjunto dos homens" (Saviani, 1995b:17). Ao considerar que o ensino da sociologia e a pesquisa sociológica provocaram "o aparecimento de uma segunda natureza humana dentro de mim", Florestan está apontando para a essência da educação, isto é, um processo que visa à transformação interna dos sujeitos pela incorporação de elementos que não são dados naturalmente e nem adquiridos espontaneamente mas que, uma vez incorporados pela mediação da ação educativa, passam a operar como se fossem naturais. Constituem, pois, um babitus, ou seja, uma disposição permanente e irreversível que passa a constituir a própria estrutura do sujeito, não lhe sendo possível agir sem que intervenham esses elementos. Trata-se, conseqüentemente, de uma segunda natureza construída pela educação sobre a base da primeira natureza transmitida por códigos genéticos e pela tradição espontânea.

Outro aspecto que ilustra a percepção do significado próprio da educação é a avaliação do papel desempenhado pela sua pesquisa de mestrado que versou sobre a Organização Social Tupinambá: "Com essa pesquisa, não só obtive o grau de mestre em ciências sociais: alcancei a estatura de um artesão que domina e ama o seu mister, porque sabe como deve praticá-lo e para o que ele serve" (Fernandes, 1977:175). Mas, por que o trabalho de mestrado viabilizou esse resultado? Isto foi possível porque, assumindo radicalmente as exigências da pesquisa, Florestan transformou seu curso de mestrado naquilo que ele devia, de fato, ser, isto é, num trabalho educativo de iniciação à formação do pesquisador (embora a maioria dos cursos de mestrado até hoje não se tenha ainda dado conta disso). Com efeito, diferentemente do que ocorre na iniciação cientifica em nível de graduação, que não implica necessariamente a realização, por parte 
de cada um dos alunos, de um projeto próprio e completo de investigação, no caso do mestrado é exatamente disso que se trata: "a iniciação será feita mediante a realização de um trabalho completo de investigação. Para a maioria dos alunos será, de fato, o primeiro trabalho de pesquisa que ele cumpre, abarcando todas as etapas implicadas no tipo de investigação encetada. Portanto, caberá ao aluno, com o auxílio do orientador e a partir de alternativas delineadas em função do estágio de conhecimento em que se encontra a área correspondente, realizar a escolha do tema, a formulação do problema, a delimitação do objeto assim como o estabelecimento da metodologia e respectivos procedimentos de análise, redigindo, em conseqüência, o texto correspondente com uma estrutura lógica adequada à compreensão plena, por parte dos leitores, do assunto tratado" (Saviani, 1991:163).

Tal entendimento corresponde inteiramente ao efeito produzido pelo trabalho de mestrado de Florestan em sua formação de pesquisador, como se constata através da avaliação feita por ele mesmo: "Descobri que nenhum sociólogo é capaz de realizar o seu ofício antes de percorrer todas as fases de um projeto de investigação completo, no qual transite do levantamento de dados à sua crítica $\mathrm{e}$ à sua análise $\mathrm{e}, \mathrm{em}$ seguida, ao tratamento interpretativo propriamente dito" (Fernandes, 1977:175).

Dir-se-ia que, até aqui, tratou-se antes do caráter educativo da pesquisa na formação do pesquisador e não propriamente do ensino enquanto processo educativo. Mas o próprio Florestan se encarrega de afastar essa possível objeção ao afirmar, em seguida: "Nem por isso a experiência em nível de ensino teve uma importância menor para mim. Ao contrário, a sala de aula logo se tornaria, em termos de formação e de amadurecimento intelectuais, uma espécie de equivalente do laboratório" (Ibid::175). E, ao relatar o processo de superação das primeiras dificuldades, revela, agora pelo ângulo de sua própria experiência docente, compreensão clara da diferença entre pesquisa e ensino e das suas relações recíprocas no interior do processo educativo: "Como o pesquisador, o professor precisa reduzir o conhecimento acumulado previamente ao que é essencial e, mais que o pesquisador, deve defrontar-se com o dever de expor tal conhecimento de modo claro, conciso e elegante (...). Ao atingir esse patamar, o ensino perdeu, para mim, o caráter de um 'fardo' e a relação com os estudantes passou a ser altamente provocativa e estimulante para o meu progresso teórico como sociólogo" (Ibid::176). E nesse contexto se delineia com clareza o lugar próprio dos cursos de graduação no processo formativo: "A fase inicial foi dura para mim e para os estudantes. Como todo professor jovem, eu não estava preparado para ensinar em cursos de graduação. Esses cursos, em nível introdutório, requerem professores de longo tirocínio, maduros no trato com a matéria e com o ensino" (Ibid.:176). 
Sobre a base dessas constatações foi possível introduzir alterações na própria estrutura do ensino de sociologia vigente dando um caráter formativo para os cursos introdutórios e organizando os cursos monográficos segundo critérios que transcendiam as preferências individuais dos professores, com evidentes vantagens não apenas para os estudantes mas também para os próprios professores: "Como os cursos de introdução se tornaram 'formativos', lecioná-los significava adquirir um domínio maior sobre os conhecimentos básicos de sociologia. Ao mesmo tempo, os cursos monográficos - determinados acima das preferências individuais dos professores - surgiam como uma vantajosa alternativa de autorealização profissional. O professor era praticamente forçado a conquistar novos espaços, além e acima de uma especialização unilateral e estreita" (Ibid.:177).

Atuando não apenas como um simples professor mas como verdadeiro educador, Florestan transformou a cadeira de Sociologia I num espaço educativo por excelência cujos influxos significativos extrapolaram os limites da instituição que a sediava, irradiando-se pelo país e repercutindo inclusive no exterior.

\section{O cientista e a educação}

Quando Florestan Fernandes completava o seu processo de iniciação à ciência sociológica, convertendo-se de aprendiz de sociólogo em sociólogo maduro com a conclusão de sua dissertação sobre $A$ organização social dos Tupinambá em 1946, ele assumiu no Jornal de São Paulo uma sessão semanal dedicada às ciências sociais, sob o nome "Homem e Sociedade". Nessa sessão publicou em $5 / 3 / 46$, a matéria denominada "A educação no interior do Brasil" em que aplica o conceito sociológico de "demora cultural" para se referir ao nosso atraso educacional, tecendo considerações a partir das informações contidas no livro Viagem ao Tocantins de Júlio Paternostro. Este artigo foi, em 1960, incluído no livro Mudanças sociais no Brasil, no qual também se encontram dois outros estudos diretamente ligados à educação: "A educação como fator de integração política", escrito em 1954 e "A utilidade da educação e das ciências sociais", de 1959 , que integra o capítulo "O homem e a cidade-metrópole" no qual, além do item mencionado, que fecha o capítulo, discute os aspectos ecológico, demográfico, econômico, social e institucional da cidade de São Paulo.

Já no primeiro texto - de 1946 - deixa evidentes as esperanças que depositava na educação: "Está mais do que patente que não sairemos do marasmo econômico e político sem transformarmos, de forma profunda e geral, o nosso sistema de ensino" (Fernandes, 1960a:121). A mesma expectativa está presente no texto de 1954: “...a intervenção do Estado, com propósito definido de ajustar o sistema educacional brasileiro às necessidades mais urgentes da vida política nacional, poderia alcançar dois efeitos presumíveis. Primeiro, criar condições dinâmicas essencialmente favoráveis à transição de uma ordem democrática 
incipiente para uma ordem democrática plenamente constituída. (...). Segundo, concorrer ativamente para que essas condições dinâmicas se reproduzam similarmente, provocando efeitos socializadores relativamente uniformes, nos diferentes tipos de comunidades brasileiras" (Ibid.:103). E o texto de 1959 reitera as mesmas esperanças: "A educação é, naturalmente, o elemento crucial para o reajustamento do homem a situações sociais que se alteram celeremente, como aconteceu em São Paulo"(Ibid.:280-281).

Em Ensaios da sociologia geral e aplicada, livro publicado em 1960, Florestan incluiu o trabalho "A ciência aplicada e a educação como fatores de mudança cultural provocada", escrito em 1958 para o Symposium sobre os Problemas Educacionais Brasileiros, que ele mesmo organizou para o Centro Regional de Pesquisas Educacionais de São Paulo. Nesse texto, após esclarecer do ponto de vista da ciência sociológica os conceitos de Ciência aplicada, educação e mudança cultural provocada, o autor passa a discutir três temas fundamentais: "Primeiro, em que sentido é possível encarar a ciência aplicada e a educação como fatores sociais construtivos. Segundo, como opera o elemento racional na mudança cultural espontânea. Terceiro, como se comporta o elemento racional quando as condições de mudança cultural podem ser submetidas a controle exterior inteligente" (Fernandes, 1960b:172-173). As análises do autor confluem para a caracterização daquilo que chama de "dilema educacional brasileiro" determinado pela situação de subdesenvolvimento o qual, ao mesmo tempo, coloca necessidades que exigem a intervenção da educação e obstáculos a que essa intervenção se efetive. Isso é ilustrado por um exemplo: "A estabilidade e a evolução do regime democrático estão exigindo a extensão das influências socializadoras da escola às camadas populares e a transformação rápida do estilo imperante de trabalho didático, pouco propício à formação de personalidades democráticas" (Ibid.:196-197). No entanto, limitando a procura, rejeitando os candidatos à escolarização e resistindo à mudança interna, o próprio "sistema educacional brasileiro inclui-se entre os fatores adversos a esse desenvolvimento. Por conseguinte, em vez de acelerar a difusão e o fortalecimento dos ideais de vida, consagrados legalmente, ele interfere no processo como fator de demora cultural" (Ibid.:197). Em suma, o "dilema" consiste em que o sistema educacional brasileiro é constituído por "instituições deficientes de ensino, que requerem alterações complexas, onerosas e profundas" e, no entanto, não pode contar senão com "meios de intervenção insuficientes para fazer face, com expectativas definidas de sucesso, às exigências práticas da situação" (Ibid.:197).

A partir do quadro acima esboçado, Florestan passa a tratar do último ponto relativo à cooperação entre educadores e cientistas sociais quando examina minuciosamente "como os cientistas sociais devem encarar sua participação e responsabilidade nos projetos de reconstrução do sistema educacional brasileiro". 
Em 1966 Florestan publica Educação e sociedade no Brasil, um alentado volume (644 páginas) em que reúne estudos sobre questões educacionais produzidos entre 1946 e 1962. Como esse livro, infelizmente, já não circula como seria desejável, convém apresentar um apanhado geral do conteúdo nele tratado.

A obra foi organizada em quatro partes. A primeira, "A Educação na Sociedade Brasileira", contém oito estudos. O primeiro decorreu de relatório preparado para o II Congresso Sindical de Trabalhadores de São Paulo efetuando um "balanço da situação atual do ensino primário, médio e superior" feito em 1960. O segundo, "A escola e a ordem social", resultou de conferência proferida em 24/9/60 na Biblioteca Municipal de São Paulo. "Mudança social e educação escolarizada" constituiu a aula inaugural do ano letivo de 1961 da Universidade do Ceará, proferida em 5/3/61. O quarto estudo, "A educação como problema social" data de 1960. "A crise do ensino" constituiu a resposta ao inquérito sobre a situação do ensino no Brasil promovido pela Revista Anbembi. O sexto estudo, "A democratização do ensino" foi o trabalho apresentado na I Convenção Estadual de Defesa da Escola Pública em 5/5/60. "O problema da juventude" consistiu no discurso de paraninfo proferido em 19/12/62 na formatura dos ginasianos do Colégio Estadual de Paraguaçu Paulista. E o último, "Notas sobre a educação na sociedade Tupinambá" decorreu dos apontamentos feitos em 1951 para exposição aos alunos da Faculdade de Filosofia, Ciências e Letras da USP.

Na segunda parte, "Dilemas do ensino superior", estão reunidos dez textos. Os três primeiros, "O destino das universidades", "Pesquisa e ensino superior" e "Os professores estrangeiros", foram redigidos em 1958. Os dois seguintes tratam, respectivamente, dos aspectos estruturais (1958) e das lições pedagógicas (1959) da crise de crescimento da Faculdade de Filosofia Ciências e Letras da USP. O sexto texto, "A representação dos alunos", data de 1962 e "A universidade e o desenvolvimento do Nordeste" foi escrito em 1961. "Liberdade de pensamento e ensino universitário" é o discurso de paraninfo da turma de formandos de 1957 da Faculdade de Filosofia, Ciências e Letras. Por último, "Universidade de Brasília" constitui o depoimento sobre o projeto de criação da UnB, concedido à Revista Anbembi em 1961.

A terceira parte, "A conspiração contra a escola pública" reúne treze textos escritos entre 1959 e 1962, todos eles ligados seja à campanha em defesa da escola pública, ou seja, ao exame crítico do projeto de Lei de Diretrizes e Bases da Educação Nacional.

A quarta parte, "Problemas educacionais da atualidade", abrange onze estudos. Com exceção do primeiro, "Os educadores e as exigências educacionais do presente", escrito em 1959; do quarto, "O Centro Brasileiro de Pesquisas 
Educacionais" (1955); do oitavo, "Uma experiência promissora"; e do décimo, "Implicações educacionais do desarmamento infantil" (1958), os demais resultam de resenhas publicadas no Suplemento Literário do jornal $O$ Estado de $S$. Paulo entre 1957 e 1962, além do segundo texto que resultou de comentários, publicados em 1946 no Jornal de São Paulo, sobre a obra de Fernando de Azevedo.

O esboço apresentado, pela amplitude dos temas abordados, dá uma idéia do lugar que ocupava a educação nas preocupações de Florestan Fernandes.

Com exceção do texto que versa sobre a educação assistemática entre os Tupinambá, o qual resultou de pesquisa desenvolvida rigorosamente segundo os cânones da ciência sociológica e motivada por interesse puramente científico, "as demais produções revelam o sociólogo empenhado nas diferentes lides intelectuais, que lhe são atribuídas na sociedade brasileira do presente" (Fernandes, 1966:xV). Por isso o autor classifica a maioria dos ensaios reunidos no livro como "para-sociológicos". Para ele os estudos reunidos na primeira parte são os que "possuem maior alcance sociológico, pois permitem considerar empiricamente a situação do ensino no Brasil, analisada em termos quantitativos e qualitativos, e apreciar objetivamente a natureza de nossa herança educacional" (Ibid.: XVII). De fato, de modo especial o primeiro estudo, fortemente apoiado em dados obtidos nas fontes disponíveis, fornece diagnóstico bastante preciso da situação educacional brasileira da época, do qual são extraídas conclusões pertinentes. Mas ao longo de toda a obra sobressai a figura do sociólogo crítico e militante, que encara a educação seja como objeto de análise científica seja como campo de intervenção prática, ambos os aspectos requerendo, de forma articulada, a contribuição do sociólogo e sua colaboração com os educadores na obra de reconstrução do sistema educacional brasileiro.

\section{O militante da educação pública}

Pode-se considerar que a militância educativa de Florestan Fernandes remonta aos anos quarenta, seja na condição de estudante e professor universitário, seja nas publicações pela imprensa ou como membro do Partido Socialista Revolucionário de orientação trotskista. Isto pode ser ilustrado através dos artigos publicados na sessão semanal "Homem e Sociedade" do Jornal de São Paulo, em 1946, como também pelo Relatório encaminhando "Sugestões para o desenvolvimento das ciências humanas" entregue em maio de 1955 a Anísio Teixeira então Diretor da CAPES e pelo "Relatório sobre a situação do ensino de ciências sociais na USP encaminhado em 2 de abril de 1956 a Jânio Quadros, então governador do estado de São Paulo (Fernandes, 1977:94-104), além de sua participação, como relator, em Comissões da Faculdade de Filosofia, Ciências e Letras da USP. 
Entretanto, é com a "Campanha em Defesa da Escola Pública" desencadeada em 1959 em torno da discussão e aprovação do Projeto de Lei de Diretrizes e Bases da Educação Nacional, que sua condição de militante da educação pública aflora plenamente projetando-se por todo o país. Com efeito, Florestan Fernandes constituiu a liderança mais expressiva e combativa do movimento em defesa da escola pública naquele período. Isto é reconhecido expressamente por Roque Spencer Maciel de Barros, outro líder do movimento. Na coletânea de textos e documentos que organizou em 1960 sob o título Diretrizes e Bases da Educaf̧ão, fez estampar a seguinte nota: "Não podemos deixar de registrar o trabalho pertinaz do professor Florestan Fernandes, levando para todos os cantos de nosso estado - e mesmo para outras unidades da Federação uma palavra de esclarecimento sobre os defeitos e perigos do projeto que a Câmara dos Deputados aprovou em janeiro último, numa autêntica 'peregrinação cívica e pedagógica' que é um fato inédito nos anais de nossa história da educação. Dezenas e dezenas de conferências fez o professor Florestan Fernandes, tornando-se credor da admiração e simpatia de todos os que lutam pela causa da educação nacional" (Barros, 1960: XXIII ).

O próprio Florestan, ao se referir aos trabalhos que produziu durante a campanha irá, em 1963, afirmar que os mesmos foram escritos "ao longo de uma tormentosa e intensa atividade intelectual, na qual me empenhei de corpo e alma". E acrescentará, algumas linhas abaixo: "Tudo se passou como se me transformasse, de um momento para outro, em porta-voz das frustrações e da revolta dos meus antigos companheiros da infância e da juventude". E recordando sua origem de menor trabalhador e filho de lavadeira, prossegue: "O meu estado de espírito fez com que o professor universitário falasse em nome do filho da antiga criada e lavadeira portuguesa, o qual teve de ganhar a sua vida antes mesmo de completar sete anos, engraxando sapatos ou dedicando-se a outras ocupações igualmente degradadas, de maneira severa, naquela época" (Fernandes, 1966: XIX). Lembrando Patrocínio e a Campanha Abolicionista, afirma: "como a ele, coube-me o dever de levar ao mundo cultivado do Brasil as angústias, os sentimentos e as obsessões dos esbulhados, e honro-me ao lembrar que não trepidei, por um instante, diante dos imperativos desse dever" (Ibid.: $\mathrm{xx}$ ). Considera que foi como "representante fortuito das massas populares" que se empenhou nessa luta: "Professor, sociólogo e socialista - não foi de nenhuma dessas condições que extraí o elemento irredutivelmente inconformista, que deu sentido à participação que tive na Campanha de Defesa da Escola Pública. Se em nenhum momento traí qualquer uma dessas condições, devo reconhecer francamente que elas foram circunstanciais e acessórias. Elas apenas me ajudaram a compreender melhor aquele dever e me incentivaram a servi-lo de um modo que me seria inacessível de outra forma" (Ibid.: XX). 
Mas se Florestan foi incontestavelmente o líder máximo da Campanha, ele não detinha a hegemonia daquele Movimento. Com efeeito, pode-se identificar, grosso modo, entre os defensores da escola pública, três grupos distintos: os liberais-pragmatistas, os liberais-idealistas e os de tendência socialista. Os primeiros provêm do movimento da Escola Nova e se encontram na origem do projeto da lei de Diretrizes e Bases da Educação Nacional elaborado em 1948. Entre eles se situam Fernando de Azevedo, Lourenço Filho, Almeida Júnior, Faria Góis e Anísio Teixeira o qual esteve mais em evidência durante a Campanha, em razão dos ataques que vinha sofrendo, na condição de diretor geral do INEP (Instituto Nacional de Estudos Pedagógicos), por parte dos defensores da Escola Particular. O segundo grupo era composto por professores da UsP ligados ao jornal $O$ Estado de S. Paulo, como Roque Spencer Maciel de Barros e Laerte Ramos de Carvalho, que redigiam os editoriais de educação do jornal, João Eduardo Rodrigues Villalobos e o próprio diretor e proprietário de $O$ Estado de S. Paulo, Júlio de Mesquita Filho. No terceiro grupo se situavam os professores ligados a Florestan Fernandes através da Cadeira de Sociologia, como Fernando Henrique Cardoso e Octavio Ianni, além de outros não-vinculados à referida cadeira, como Wilson Cantoni.

Os dois primeiros grupos têm em comum a referência ao liberalismo, mas se distinguem quanto ao modo como encaram a ideologia liberal. Os liberaisidealistas partem de uma idéia essencialista de homem, encarado como um ser de caráter absoluto e sagrado que se afirma como indivíduo dotado de liberdade, originalidade e autonomia: "o homem é sagrado, seja essa sacralidade função de sua origem divina, seja decorrência de sua própria liberdade, que o transforma num ser original no mundo e em fundamento dele" (Barros, 1971:242-243). Portanto, a educação deve ter como objetivo supremo a afirmação da liberdade, originalidade e autonomia ética do indivíduo. Os liberais-pragmatistas, por sua vez, partem de uma visão de homem centrada na vida, na existência, na atividade. Por isso não invocam razões baseadas num suposto caráter absoluto do ho$\mathrm{mem}$. Seus argumentos são sempre de ordem prática. Defendem a escola pública em função de sua maior eficiência para responder às necessidades postas pela sociedade constituída já que, para eles, cabe à educação a tarefa de adequar os indivíduos à sociedade. Já a tendência socialista, partindo da consideração de que os homens constituem, social e historicamente, um processo contraditório marcado por conflitos e lutas, via na escola pública um instrumento eficaz no processo de superação do subdesenvolvimento econômico, social, político e cultural próprio da sociedade brasileira. Assim, enquanto na visão de educação dos liberais-idealistas o indivíduo tem precedência sobre a sociedade e os liberaispragmatistas buscam educar os indivíduos para ajustá-los à sociedade em mudança, os de tendência socialista entendem a educação em suas relações recíprocas com a sociedade o que significa que o processo educativo deve ser dirigido não apenas à adaptação mas à transformação social. 
Ora, o grupo hegemônico no movimento de defesa da escola pública foi, inegavelmente, o dos liberais-idealistas. $\mathrm{E}$ para isso concorreu, sem dúvida, o fato de terem sob seu controle um poderoso órgão de imprensa, o jornal $O$ Estado de S. Paulo colocado prioritariamente a serviço do movimento. Aliás, o professor Florestan Fernandes tinha clara consciência disso como revela a seguinte passagem: "Participam da Campanha de Defesa da Escola Pública pessoas de diferentes credos políticos. Pois bem, nenhum de nós deu precedência às suas convicções íntimas sobre o objetivo comum. Limitamo-nos a defender idéias e princípios que deixaram de ser matéria de discussão política nos países adiantados. Tudo se passa como se o Brasil retrocedesse quase dois séculos, em relação à história contemporânea daqueles países, e como se fôssemos forçados a defender, com unhas e dentes, os valores da Revolução Francesa! É uma situação que seria cômica, não fossem as consequiências graves, que dela poderão advir. A nossa posição pessoal pesa-nos como incômoda. Apesar de socialista, somos forçados a fazer a apologia de medidas que nada têm a ver com o socialismo e que são, sob certos aspectos, retrógradas" (Fernandes, 1966:427).

A condição de militante da educação prossegue através de outras intervenções em momentos significativos de nossa história educacional como a momentosa questão da reforma universitária entre 1964 e 1969 quando profere conferências, concede longos e analíticos depoimentos culminando com o texto "Os dilemas da reforma universitária consentida" (Fernandes, 1975:201-242) que resultou de conferência proferida em 11/10/68 no I Forum de Professores sobre a "Política Educacional do Governo", portanto, antes da aprovação em 28/11/68, da Lei 5.540 que implantou a referida Reforma. Após uma análise aguda, lúcida e pertinente dos problemas da reforma, o texto se encerra com o tópico "O que fazer?" deixando claro que todo o rigor da análise é posto a serviço da luta pela "criação de uma universidade capaz de operar através de si mesma, de preencher todas as funções que deve satisfazer sob a civilização urbano-industrial, de ser uma fonte de consciência histórica crítica e de pensamento inventivo (na ciência ou demais formas de saber), de converter-se em um dos eixos da revolução democrática" (Fernandes, 1975:241-242).

Insere-se também nesse contexto da militância o livro $A$ questão da USP (Fernandes, 1984) publicado por ocasião da comemoração do centenário da Universidade de São Paulo, que reconstrói a história dessa universidade sob o prisma das lutas que se travaram em seu interior em termos políticos, culturais, pedagógicos e institucionais. Como essas lutas foram por ele próprio protagonizadas em larga escala, o livro assume em diversos momentos a característica de depoimento.

Essa militância retoma, porém, a luta mais ampla pela educação pública popular, a partir de 1986 quando Florestan é eleito para o Congresso Constituinte 
e participa intensamente da elaboração do capítulo da educação na Constituição promulgada em outubro de 1988 e, em seguida, do processo de elaboração, discussão e aprovação do projeto da nova Lei de Diretrizes e Bases da Educação Nacional, iniciado em dezembro de 1988. Sua atuação direta se estendeu até 1994 quando se completou o seu segundo mandato como deputado federal.

\section{O publicista da causa educativa}

Florestan, a par da produção de conhecimentos e da sua transmissão através do ensino institucionalizado, não descurou de sua difusão, da forma a mais ampla possível, para o conjunto da sociedade. Dir-se-ia que ele cumpriu magistralmente e em sentido crítico e revolucionário aquilo que se define correntemente como as três grandes funções da universidade: a pesquisa, o ensino e a extensão. Para ele constituía verdade prática, internamente incorporada como uma espécie de segunda natureza, a consideração de Gramsci segundo a qual "criar uma nova cultura não significa apenas fazer individualmente descobertas 'originais'; significa, também, e sobretudo, difundir criticamente verdades já descobertas, 'socializá-las' por assim dizer; transformá-las, portanto, em base de ações vitais, em elemento de coordenação e de ordem intelectual e moral. $O$ fato de que uma multidão de homens seja conduzida a pensar coerentemente e de maneira unitária a realidade presente, é um fato 'filosófico' bem mais importante e 'original' do que a descoberta, por parte de um 'gênio filosófico', de uma nova verdade que permaneça como patrimônio de pequenos grupos intelectuais" (Gramsci, 1977:6).

Florestan, ao longo de sua trajetória, freqüentou assiduamente a imprensa escrita, divulgando incansavelmente um saber crítico da sociedade encarado como instrumento para a necessária ação transformadora a ser protagonizada pelos debaixo. Os textos relacionados à educação e que cobrem principalmente o período da década de 80 foram reunidos no livro $O$ desafio educacional, publicado em 1989. No prefácio o autor afirma: "Este livro reúne artigos que apanham aspectos da erupção de um vulcão que parecia extinto. A mensagem do autor aparece, aqui e ali, como proposta de esclarecimento de processos interrompidos de mudança educacional (...) Artigos de jornal ou de revista, textos de conferências, entrevistas e ensaios revelam o publicista que se empenha em debates ou em pugnas que clamam por uma revolução educacional" (Fernandes, 1989:9-10).

Em verdade foi nesse trecho que me inspirei para o título deste tópico. $O$ livro em questão se divide em duas partes. A primeira reúne 28 textos sob o título de "A crise do ensino: contrastes do crescimento sem democracia". A segunda contém oito textos encabeçados pelo título "O professor e a transformação do concreto". Na primeira parte o tema predominante é a nova lei de diretrizes e bases da educação. A segunda é dominada pela apresentação de projetos de dispositivos constitucionais que ocupa quatro dos oito textos. 
O livro A transif̧ão prolongada: o periodo pós-constitucional reúne 94 artigos publicados na imprensa diária entre 3 de novembro de 1988 a 9 de abril de 1990. Os artigos estão agrupados em sete conjuntos temáticos. A sexta parte, "Educação, ciência e tecnologia" contém os artigos mais diretamente ligados à educação. Em "O debate sobre a Lei de Diretrizes e Bases", publicado no Jornal do Brasil em 1/11/89, Florestan situa o nível em que se encontravam as discussões, para concluir: "Não devemos alimentar ilusões. Os embates vão recomeçar, de modo negativo, tanto na Comissão, quanto na sociedade. É uma pena, permaneceremos presos ao passado. Só que nos cumpre fazer tudo o que for possível para não ficarmos com 'meia vitória'. Precisamos cortar o nó górdio de nossa história. Os conservadores escolheram a educação como o terreno de luta principal. Façamos a sua vontade. Porém, para vencermos de uma vez por todas!" (Fernandes, 1990:211).

Efetivamente, apesar de ver com clareza a magnitude dos impasses e obstáculos, Florestan colocou fortes esperanças na possibilidade de transformação do nosso quadro educacional a partir da conjuntura que se abria com a Nova Constituição e a Nova Lei de Diretrizes e Bases da Educação Nacional. Por isso não poupou esforços nem a saúde, já debilitada, na luta que travou até o último momento. Sua coluna semanal na Folha de S. Paulo saiu regularmente durante seis anos, de 26 de junho de 1989 a 7 de agosto de 1995. Nem a proxidade da morte impediu essa regularidade, pois os três últimos artigos foram publicados já após o seu falecimento.

\section{Conclusão}

O objetivo deste artigo foi propiciar aos leitores uma idéia geral da importância de Florestan Fernandes para o desenvolvimento da educação em nosso país. Para tanto procurou-se, o quanto possível, basear-se nas suas próprias obras, organizando a exposição a partir de quatro aspectos entendidos como marcantes em sua trajetória: o educador, o cientista, o militante e o publicista. No entanto, advertiu-se preliminarmente sobre a unidade e coerência dessa trajetória que entrelaça fortemente aqueles aspectos, os quais se influenciam reciprocamente.

Acredita-se ter ficado clara ao leitor a forte relação de reciprocidade entre a trajetória do professor e do cientista. Também não terá escapado a relação entre o cientista $\mathrm{e}$ o militante, à medida em que o instrumental teórico, empírico e analítico amealhado pelo cientista era posto a serviço da militância. Convém, porém, explicitar um pouco mais como o militante e, por conseqüência, também o publicista exerceram influência decisiva sobre a trajetória do cientista.

Conforme depoimento do próprio Florestan, a "falta de um sólido movimento socialista revolucionário" como é o caso do Brasil, cria entraves ao desenvolvimento da consciência científica no campo da sociologia. "Por isso, demorei 
algum tempo para vencer certas limitações descritivas e interpretativas" (Fernandes, 1977:199). E, na página seguinte: “Contudo, eu teria demorado ainda mais (...) não fossem dois elementos externos, que tiveram profunda influência no meu relacionamento com a sociologia brasileira" (Ibid.:200). Desses dois elementos, o segundo, de caráter empírico e teórico, refere-se às pesquisas desenvolvidas junto à cadeira de Sociologia I. Aqui interessa destacar o outro elemento.

Esse primeiro elemento é definido como de caráter prático e está ligado ao envolvimento na Campanha em Defesa da Escola Pública graças à qual Florestan mobilizou "as vantagens da condição de sociólogo militante para observar, analisar e interpretar o meio ambiente". Diz ele: "Tive contatos intensos e profundos com os diferentes setores da sociedade brasileira, dos operários e estudantes às elites liberais e tradicionais, dos educadores, jornalistas e líderes sindicais aos maçons, espíritas, pastores protestantes e sacerdotes católicos. Descobri os véus de um quadro sombrio e doloroso"(Ibid.:200).

E em que consistia esse quadro? Na seqüência do texto são indicados concisamente os elementos configuradores do quadro descoberto: "As debilidades das correntes radical-democráticas; as deficiências do movimento socialista; a violência e o obscurantismo da reação conservadora; a neutralização do Legislativo e do Executivo por interesses particularistas regionais ou de classe e setoriais, todos fundamentalmente egoístas e antinacionais; uma persistente 'reação sociopática à mudança social', que submetia todas as inovações de significado político ao mais cruel e cego controle de classe" (Ibid.:200). "

O quadro assim esboçado o conduz à seguinte conclusão: "Pela primeira vez em minha vida era provocado a definir a consciência burguesa em termos de uma equação concreta, que me ensinava que o controle burguês da sociedade civil estava bloqueando e continuaria a bloquear de modo crescente, no Brasil, a revolução nacional e a revolução democrática de recorte especificamente capitalista" (Ibid::200).

A experiência prática de militância em defesa da escola pública foi, pois, decisiva na formação e amadurecimento do cientista. E, aliada aos elementos teóricos e empíricos decorrentes das investigações desenvolvidas em articulação com seu grupo de pesquisa, tornou possível a elaboração de $A$ revolução burguesa no Brasil: ensaio de interpretação sociológica (Fernandes, 1975b), obra densa e madura, com certeza o coroamento da produção científica de Florestan Fernandes.

Este artigo se iniciou com a frase: "Pode-se dizer que as preocupações educacionais acompanham toda a trajetória de Florestan Fernandes...". Pois bem. O Prefácio a $O$ desafio educacional começa com a seguinte frase: "A educação sempre fez parte de minhas cogitações intelectuais e práticas" (Fernandes, 1989:7). 
Tal preocupação se manifesta também num de seus últimos artigos publicado no número especial da Revista da ADUSP, a ele dedicado, no qual, tratando da relação entre universidade e talento ele afirma: "O maior erro que ocorreu na USP foi o de conferir à antiga Faculdade de Pedagogia e à Licenciatura o segundo plano, de companheiros de viagem de terceira qualidade. Desde o início a Pedagogia deveria, pelo menos, ter uma preeminência à Filosofia" (Fernandes, 1995a:11).

E na entrevista que concedeu à Folba de S. Paulo pouco antes de falecer, respondendo a uma pergunta sobre a globalização da economia, afirmou: "Os efeitos previsíveis desse processo em marcha é a herança bárbara que se choca com as aspirações de igualdade, liberdade, democracia, cidadania, universalização da educação de qualidade e tudo o mais" (Fernandes, 1995b:5). E, em seguida, aponta o caminho que se apresenta como alternativa a essa tendência de barbarização: "Os socialistas não são, como muitos insistem, equivalentes dos dinossauros em busca de nova glaciação. Ao contrário, detêm os meios de análise dos processos que estão em efervescência e, ao mesmo tempo, lutam pelas alternativas que restam à humanidade em virtude da incapacidade do capitalismo de responder positivamente às exigências mínimas do viver coletivo com dignidade" (Ibid.:5).

A prática educativa, a produção científica, a militância incansável e a tenaz ação do publicista Florestan Fernandes permanecem como uma contribuição inestimável e sua figura coerente e íntegra constitui um exemplo a impulsionar as lutas que somos impelidos a continuar travando para criar uma sociedade capaz de atender "às exigências mínimas do viver coletivo com dignidade" entre as quais se inclui a "universalização da educação de qualidade". Trata-se de uma luta árdua que encontrará pela frente toda a sorte de obstáculos. Com efeito, sintomaticamente, na parte que trata de "Educação, ciência e tecnologia" no livro $A$ transição prolongada, figura como epígrafe: "As aparências mudam - a realidade reproduz-se atavicamente" (Fernandes, 1990:203).

Referências bibliográficas

BARROS, Roque Spencer Maciel de (org.). Diretrizes e Bases da Educaf̧ão. São Paulo, Pioneira, 1960.

Introdução à filosofia liberal. São Paulo, Grijalbo/Edusp, 1971.

BOURDIEU, Pierre \& PASSERON, Jean-Claude. La reproduction: éléments pour une théorie du système d'enseignement. Paris, Minuit, 1970 (tradução brasileira: Rio de Janeiro, Francisco Alves, 1975). 
CONDORCET. Cinq mémoires sur l'instruction publique. Paris, Edilig, 1989.

FERNANDES, Florestan. Mudanças sociais no Brasil. São Paulo, Difel, 1960a.

. Ensaios de sociologia geral e aplicada. São Paulo, Pioneira, $1960 \mathrm{~b}$.

- Educação e sociedade no Brasil. São Paulo, Dominus/Edusp, 1966.

1975a. - Universidade brasileira: reforma ou revolucãa? São Paulo, Alfa-Ômega, - A repolução burguesa no Brasil. Rio de Janeiro, Zahar, $1975 b$.

- A sociologia no Brasil. Petrópolis, Vozes, 1977.

. 'A questão da USP. São Paulo, Brasiliense, 1984.

- O desafio educacional. São Paulo, Cortez, 1989.

- A transição prolongada. São Paulo, Cortez, 1990.

especial).

. Universidade e talento. Revista Adusp, n. 4, p. 8-11, out. 1995 (edição

. Entrevista à Folha de S. Paulo, Caderno Mais! 20 ago. 1995, p. 4-5.

FROM, Erich. Conceito marxista do bomem. 4a . ed. Rio de Janeiro, Zahar, 1967:

GRAMSCI, Antonio, Il materialismo storico e la filosofia di Benedetto Croce. Roma, Riuniti, 1977 (trad. brasileira: Concepsãa dialética da bistbria, $2^{\mathrm{a}}$. ed. Rio de Janeiro, Civilização Brasileira, 1978).

SAVIANI, Dermeval. Concepção de dissertação de mestrado centrada na idéia de monografia de base. Educação Brasileira, Brasília, v. 13, n. 27, p. 159-168, $2^{\circ} \mathrm{sem}$. 1991.

- Escola e democracia, 29ª ed. Campinas, Autores Associados, 1995a.

-. Pedagogia bistórico-crítica, 5a . ed. Campinas, Autores Associados, $1995 \mathrm{~b}$.

Resumo

No presente artigo destaca-se a importância de Florestan Fernandes para o desenvolvimento da educação brasileira. Com base em suas próprias obras, a exposição foi organizada em torno de quatro eixos: o educador, o cientista, o militante e o publicista. $O$ primeiro aspecto enfoca a figura do professor Florestan evidenciando o profundo significado educativo que marcou a sua atividade docente. $O$ segundo põe em evidência o lugar ocupado pela educação nas investigações científicas por ele realizadas. $\mathbf{O}$ terceiro eixo de análise se ocupa de seu engajamento na luta em defesa da educação pública. Finalmente, o quarto aspecto traz à tona o publicista incansável, empenhado em divulgar, sob todas as formas a seu alcance, a causa da defesa de uma escola pública de qualidade acessivel a todos os brasileiros. 


\begin{abstract}
This article highlights the important part played by Florestan Fernandes for the development of education in Brasil. Departing from his own works, my exposition has been organized around four focal points: the educator, the scientist, the activist, and the advertiser. The first aspect focuses on the figure of the teacher evincing the deep educational significance which characterized his teaching activity. The second one emphasizes the role education played in his scientific research. The third point deals with his engagement in the fight for public education. Finally, the fourth aspect brings to the surface the tireless advertiser striving to propagate, in every way within his reach, the cause of a high quality public school open to every Brazilian citizen.
\end{abstract}

Dermeval Saviani é doutor em Filosofia da Educação pela PUC-sp e Livre Docente em História da Educação pela Unicamp. Atualmente é professor titular do departamento de Filosofia e História da Educação e diretor associado da Faculdade de Educação da Unicamp. 